In Guy's Hospital, the happiest effects continue to follow the administration of the succus limoni in acute rheumatism, as recommended by $D_{r}$. Rees ; its modus operandi is said to be the conversion of uric acid, by supplying it with oxygen, into urea ; the most obvious effects produced on the system are a diminution both in the frequency and power of the pulse, and an increase in the quantity of solids excreted in the urine. The same remedy has also been applied to purpura with marked success.

As a testimonial of respect to the memory of Liston, four marble busts have been resolved upon; one to be placed in the College of Surgeons, a second in University College, a third to be sent to Edinburgh, and the fourth to be retained in the farnily. A gold medal is also to be struck. off, to be awarded annually by the Council of University College to the best proficient in surgery.

London, March, 1850. Yours, \&c. Edw. M. Field, M.D.

\title{
DR. JACKSON'S REPORT TO THE CORONER'S JURY.
}

[The following is the Report, alluded to in last week's Journal, by Dr. Charles 'T. Jackson, on the articles found in Prof. Webster's furnace.]

List of articles found in the laboratory furnace cinders, delivered to us by the jury of the Coroner's inquest at the Mass. Medical College in Boston, Dec. 1st, 1849. These articles were sorted on Sunday by Drs. Wyman, Ainsworth, and myself, Dr. Gay having been obliged to leave for the day.

Bones found in the cinders from the furnace.-Right os calcis, right astragalus, tibia and fibula phalanges, probably of the middle or ring finger. Coronoid process of lower jaw. Numerous fragments of a skull. A human tooth that had a bole in it as if once filled by dental operation. Three blocks of artificial mineral teeth were also found in the cinders, without the gold plate. A pearl shirt button was found in the ashes and was partially calcined. Numerous little cup-shaped pieces of copper, similar to some seen in one of the laboratory drawers, were also found. Many pieces of glass were mixed with the slags, and pieces of metal were found in and among the cinders.

These various articles were all completely examined, and such as needed chemical analysis were subsequently taken by Dr. Gay and myself, and examined.

The lumps of metal most abundant in the furnace cinders were teachest lead, an alloy of tin and lend, in nearly equal proportions, the tin predominating in the pieces analyzed-tin, 12,19; lead, 11,95. The cinders being pounded and worked, disclosed some small globules of gold, and an alloy of silver and gold. The amount of gold found was small, $30 \mathrm{grs}$. The amount of silver was small.

After your examination of the liuman body, committed to you, I made some chemical examinations of the surface which had been dissolved on the chest and one thigh, and found that they had been imbued with a solution of potash. This I determined by chemical analysis, finding potash and a little sea salt. There was an evident corrosion of the surface 
of the skin, by the action, probably, of the potash, aided by heat. I found potash in the skin of both the thigh and thorax, and in the muscles at each end of the dissevered thorax, 'the alkali being very strongly marked. The dark color of the skin which had been acted upon by potash, was, probably, in part colored by the tan, the potash aiding in this coloring. I found no alkali in the interior of the thigh, nor in the flesh of the back beneath the skin.

I observed that the hair on the left side of the thorax had been singed by fire. I noticed that the skin was corroded by potash, and was quite tender near the opening in the skin opposite to the sixth and seventh ribs, and that the edges of this opening appeared to have been corroded by that alkali.

I dissected out portions of the femoral arteries and flesh of both thighs, and the artery and vein of the leg, to examine, to ascertain whether the body had been injected with the fluids used for preserving bodies in the dissecting room. These I gave into the hands of Dr. Martin Gay for analysis, and he has caused an examination of one of these pieces to be made in my laboratory, by Mr. Richard Crossley, who found no traces of zinc or arsenic substances used in the preservation of bodies in the dissecting room.

The spots on the wall, floor and furniture, sbown us by the jury and police, were submitted to the examination of Dr. Jeffires Wyman, as were also the spots on a pair of pantaloons and slippers, submitted to our inspection; and his results will probably be reported to you by that gentleman.

The results to which I have arrived are, that portions of a human adult skeleton were found in the cinders and coals submitted to my examination; that tea-chest lead had been thrown into the fire; that the gold found may have been derived from the set of mineral teeth found in the fire; that the silver was in small quantity; that the skin and parts of the thorax of the body you examined had been subjected to the action of potash, and an attempt had been made to burn the thorax in the fire, but had not been persevered in.

These are all the conclusions we are authorized to draw from the premises herein set forth, and from the examinations submitted to the chemical department of your committee. Respectfully submitted,

$$
\text { By your obedient servant, C. T. Jạckson. }
$$

\section{THE BOSTON MEDICAL AND SURGICAL JOURNAL.}

BOSTON, APRIL 10,1850 .

Strictures of the Urethra.-John P. Mettauer, M.D., Prof. of Medicine and Surgery in Randolph Macon College, Virginia, has published a small memoir on "Strictures of the Urethra," which is altogether a sensible, methodical, practical guide in the treatment of a difficult line of practice; but a more miserable specimen of book-printing never emanated near 